Changes in potassium in the serum and the electrocardiogram and the effect of therapy. Pediatrics 1959;25:562-76.

2 Grylack L, Medani C, Hultzen C, et al. Non-oliguric renal failure in the newborn. A prospective evaluation of diagnostic indices. Am J Dis Child 1982;136:518-20.

3 Brion LP, Fleischman AR, McCarton C, Schwartz GJ. A simple estimate of glomerular filtration rate in low birth weight infants during the first year of life: non-invasive assessment of body composition and growth. J Pediatr 1986;109:698-707.

4 Gruskay J, Costarino AT, Polin RA, Baumgart S. Non-oliguric hyperkalemia in the premature infant weighing less than 1000 grams. J Pediatr 1988;113:381-6.
5 Shortland D, Trounce JQ, Levene MI. Hyperkalaemia, cardiac arrhythmias, and cerebral lesions in high risk neonates. Arch Dis Child 1987;62:1139-43.

6 Edvinsson L, Lou HC, Tucde K. On the pathogenesis of regional cerebral ischemia in intracranial hemorrhage: a causal influence of potassium? Pediatr Res 1986;20:478-80.

Correspondence to Dr A R Fleischman, Albert Einstein College of Medicine, Jacobi Hospital, Room 8S15, Pelham Parkway South, Bronx, New York 10461, USA.

Accepted 26 September 1988

\title{
Twinning rates and social class in Great Britain
}

\author{
M MURPHY AND B BOTTING*
}

Department of Community Medicine and General Practice, Radcliffe Infirmary, Oxford and *Medical Statistics Division, Office of Population Censuses and Surveys, London

SUMMARY We examined like and unlike sex twinning rates in Great Britain by social class over the period 1974-85. Although twinning rates are believed to have changed over that period, we found no evidence of differential change by social class, suggesting that any factors affecting twinning are widespread in the population.

A secular decline in twinning rates from the early 1950s until the 1970s has been observed almost worldwide, largely confined to dizygotic twinning. In Great Britain, as elsewhere, the dizygotic twinning rate may now have plateaued, with monozygotic twinning stable throughout or latterly increasing. While demographic change may account for part of these trends, the phenomenon is poorly understood. A number of environmental factors have been proposed, including changing patterns of use of ovulatory stimulants and the contraceptive pill and dietary exposures to pesticides or stilboestrol. ${ }^{12}$ As exposure to these agents may well have varied in different socioeconomic groups, we examined twinning rates in Great Britain, 1974-85, for any evidence of differential changes by social class.

\section{Methods and results}

We obtained numbers of like sexed and unlike sexed live and stillborn twins and total confinements 1974-85 for England and Wales from the Office of Population Censuses and Surveys (OPCS) and for Scotland from the General Register Office $(\mathrm{GRO}(\mathrm{S}))$. The data were available by father's social class for legitimate births only in Scotland, but it was possible to include jointly registered illegitimate births as well for England and Wales. This allows a larger number of births to be analysed by social class in a consistent way over a period of time when the rising number of illegitimate births raises important questions of selection bias if they are excluded from social class analysis. ${ }^{3}$

The figure shows $1974-85$ trends in like sexed, unlike sexed, and total twinning rates for England and Wales by aggregated social class, indirectly standardised for maternal age in each case using the twin rates for 1974-85 as standard. Data for 1981 for England and Wales are not available. There is little evidence of a difference in the trends in twinning rates between the non-manual and manual social classes, though twinning rates are higher in the manual group. Confidence intervals around the regression coefficients for each of the three pairs of time trends confirm this (table). Although not shown here, analysis by less aggregated social class groups (I and II, III, IV and V) showed similar patterns in both England and Wales and Scotland, though with a possibly more pronounced increase in like sexed and total twinning rates in the 1980s in social class III and the combined social classes IV and $\mathrm{V}$ particularly in Scotland.

\section{Discussion}

Discontinuities in the social class assignment of births because of change in the Registrar General's classification in 1979 are small, ${ }^{4}$ and statistical fluctuations due to small numbers of events will also have been minimised by restricting the analysis to 


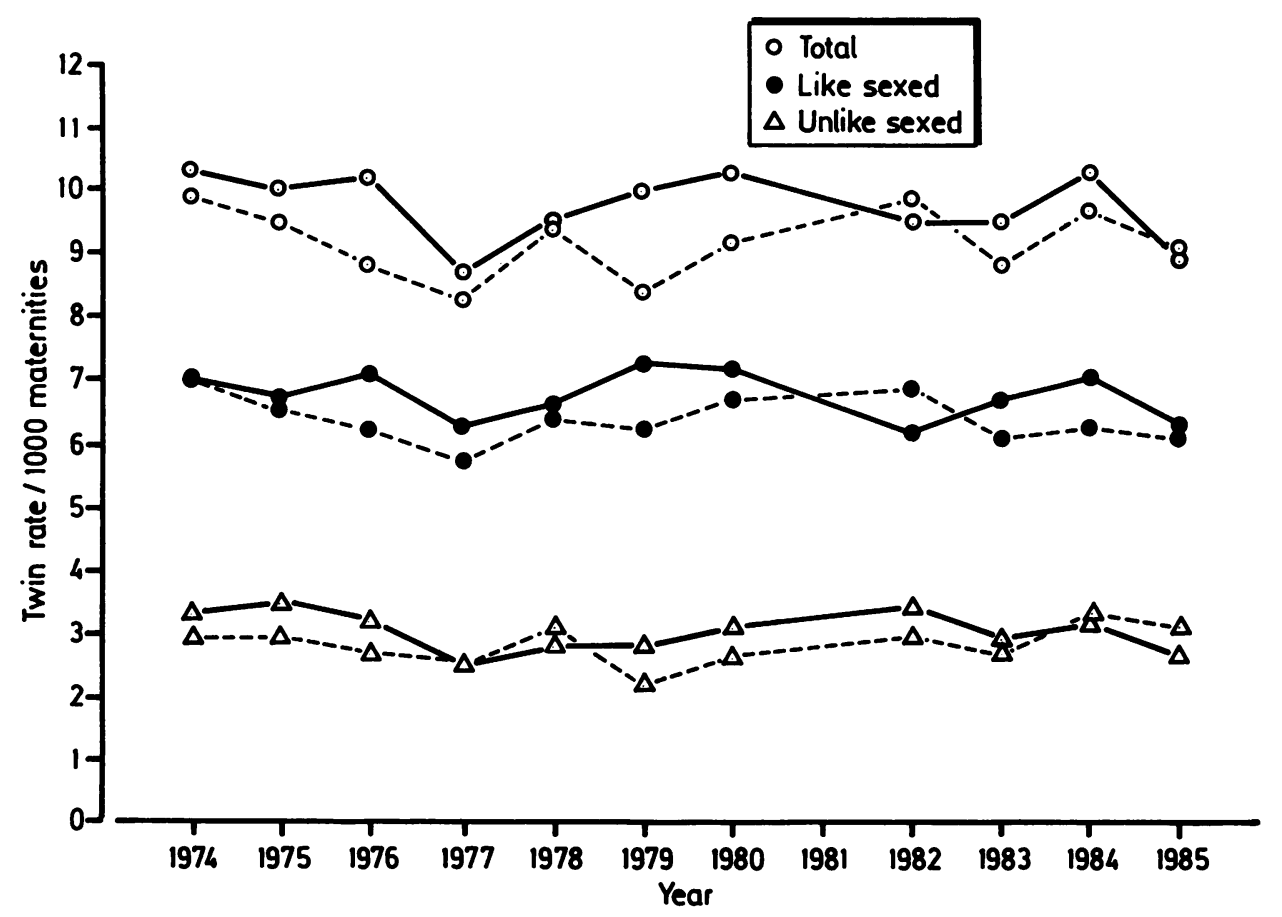

Figure Age standardised twin rates in England and Wales, 1974-85, based on legitimate and jointly registered illegitimate births combined, for non-manual (I, II, IIIn, - - -) and manual (IIIm, IV, V, - ) social class groupings.

Table Regression coefficients (and associated 95\% confidence intervals) for twinning rates 1974-85 in England and Wales (legitimate and jointly registered births)

\begin{tabular}{llll}
\hline & $\begin{array}{l}\text { Total } \\
\text { twin rate }\end{array}$ & $\begin{array}{l}\text { Like sexed } \\
\text { twin rate }\end{array}$ & $\begin{array}{l}\text { Unlike sexed } \\
\text { twin rate }\end{array}$ \\
\hline Non-manual social class (I, II, III) & +0.003 & -0.027 & +0.028 \\
& $(+0.116$ to -0.111$)$ & $(+0.049$ to -0.103$)$ & $(+0.088$ to -0.031$)$ \\
Manual social class & -0.045 & -0.020 & -0.031 \\
(IIIm, IV, V) & $(+0.060$ to -0.149$)$ & $(+0.054$ to -0.094$)$ & $(+0.029$ to -0.091$)$ \\
\hline
\end{tabular}

non-manual and manual social classes. We have less confidence in the results of the subsidiary analysis for England, Wales, and Scotland by individual social classes for these reasons. The absence of a difference in the trends between these two distinct social groupings of manual and non-manual occupations, over a period when twinning rates were changing, suggests that the factors currently affecting twinning rates are widespread in the population, as there has been previous evidence of a social class difference in Scottish twinning, at least for the dizygous. ${ }^{5}$ It is disquieting that the human reproductive system should have been so affected for so long without anyone having much evidence of the reason for it. ${ }^{1}$
We would like to thank Barry Werner of the Fertility Statistics Division, OPCS, and Christine Rae of the GRO(S) for providing the data used in the analysis. Christine Eckersley of the Department of Community Medicine and General Practice, Oxford, typed the manuscript.

The opinions expressed are not necessarily those of OPCS.

\section{References}

1 Anonymous. Worldwide decline in dizygotic twinning [Editorial]. Br Med J 1976;i:1553.

2 Botting B, Davies IM, Macfarlane A. Recent trends in the incidence of multiple births and their mortality. Arch Dis Child 1987;62:941-50.

3 Registrar General. The registrar general's decennial supplement on childhood mortality 1979-80, 1982-3. (OPCS.) London: HMSO, July 1988. 
${ }^{4}$ Werner B. Fertility trends in different social classes: 1970 to 1983. Population Trends 1985;41:5-13.

5 Smith A. Observations on the determinants of human multiple births. Supplement to the Annual Report of the Registrar General for Scotland. 1964. (Number 110.) Edinburgh: HMSO, 1966:70-82.

Correspondence to Dr M Murphy, Department of Community Medicine and General Practice, Radcliffe Infirmary, Oxford OX2 $6 \mathrm{HE}$.

Accepted 18 July 1988

\title{
Resident parents and shorter hospital stay
}

\author{
M R H TAYLOR AND P O'CONNOR* \\ National Children's Hospital and ${ }^{*}$ Department of Paediatrics, Trinity College, Dublin
}

\begin{abstract}
SUMmARY A total of 586 admissions for 12 medical conditions were reviewed. The stay of children accompanied by a resident parent was $31 \%$ shorter than those whose parents were not resident. Resident parents benefit the emotional well being of the child and increase hospital efficiency; accommodation for parents should therefore be an integral part of a unit admitting children.
\end{abstract}

The number of resident parents in the National Children's Hospital has risen from nine (accompanying $0.4 \%$ of admissions) in 1970 to 1527 (accompanying $38.9 \%$ of admissions) in 1987. It is generally recognised that children in hospital benefit from the presence of a living in parent. ${ }^{12}$ The main emphasis has been on the benefit of the child's emotional well being. The importance of the parent in dealing with the adult world of the hospital on the child's behalf has been stressed. ${ }^{2}$ In addition to these emotional benefits we noted a tendency for children with resident parents to have shorter hospital stays than those whose parents did not live in, but we were unable to find any published record of this observation. We studied the duration of stay of children admitted for a range of medical conditions with and without their parents.

\section{Patients and methods}

All admissions to the National Childrens' Hospital for medical conditions over an eight month period were reviewed. Twelve diagnostic categories were selected in which it seemed possible that a parent's ability to manage a convalescent child would result in a reduction in the hospital stay. Only the primary diagnosis was used in selecting patients. The diagnoses used are given in table 1 . As a very prolonged stay might discourage parents from living in, children with a stay of more than 14 days were excluded. This reduced the study population by 19 . The unpaired $t$ test and the $\chi^{2}$ test were used for statistical analysis. As the duration of stay data were skewed a log transformation was used in the analysis.

Resident parents lived in the hospital. Parents who spent the day in hospital but slept elsewhere were not regarded as resident.

\section{ELIGIBILITY GROUPS}

The eligibility group gives a measure of the affluence of the family. For the purpose of determining eligibility to health services in the Republic of Ireland patients are assessed according to their family income and social circumstances. The criteria used at the time of this study can be summarised as follows:

Group 1: Unemployed breadwinner; single mother; family income below $£ 90.50$ per week (with a $£ 10$ allowance for each child under 16 years old). Other social and economic factors are also taken into account.

Group 2: Family income less than $£ 11000$ per annum.

Group 3: Those not falling into groups 1 or 2 . Almost all patients in this group were covered by a medical insurance scheme.

\section{Results}

A total of 586 admissions were studied; 136 patients were accompanied by a resident parent and had a mean duration of stay of $2 \cdot 88$ days. On 450 admissions a resident parent did not accompany the child and the mean duration of stay was $4 \cdot 16$ days. The difference between these groups was highly significant (table 1). Children of affluent familes (group 3) were more likely to be accompanied by a 